\title{
Confidence and use of physical examination and point-of-care ultrasonography for detection of abdominal or pleural free fluid. A cross-sectional survey
}

\author{
Antonio Leidi ${ }^{1}$ (1) $\cdot$ Antoine Saudan ${ }^{2} \cdot$ Guillaume Soret $^{1} \cdot$ Frédéric Rouyer $^{3} \cdot$ Christophe Marti $^{1} \cdot$ Jérôme Stirnemann $^{1}$. \\ Jean-Luc Reny ${ }^{1}$. $\cdot$ Olivier Grosgurin ${ }^{1,3}$
}

Received: 14 April 2021 / Accepted: 27 May 2021 / Published online: 20 June 2021

(c) The Author(s) 2021

\begin{abstract}
Physical examination (PE) has always been a corner stone of medical practice. The recent advances in imaging and fading of doctors' ability in performing it, however, raised doubts on PE usefulness. Point-of-care ultrasonography (POCUS) is gaining ground in medicine with the detection of free fluids being one of its main applications. To estimate physicians' confidence and use of PE and POCUS for the detection of abdominal or pleural free fluid, we conducted a cross-sectional survey. In all, 246 internal and emergency medicine physicians answered to the survey (197 in-hospital physicians and 49 general practitioners; response rate 28.5\%). Almost all declared to perform PE in case of suspected ascites or pleural effusion (88\% and $90 \%$, respectively). The highest rates of confidence were observed in conventional PE signs ( $91 \%$ for diminished breath sounds, $80 \%$ for dullness to thorax percussion, and $66 \%$ for abdominal flank dullness). For the remaining signs, rates of confidence were less than 53\%. Physicians with $>15$ years of experience and POCUS-naïve doctors reported higher confidence in PE. Most of emergency and almost half of internal medicine physicians (78\% and 44\%, respectively) attended a structured POCUS course. POCUS use was higher among trained physicians for both ascites $(84 \%$ vs $50 \%, p<0.001)$ and pleural effusion $(80 \%$ vs $34 \%, p<0.001)$. Similarly, higher POCUS use was observed in younger physicians. In conclusion, PE is frequently performed and rates of confidence are low for most PE signs, especially among young doctors and POCUS users. This detailed inventory suggests an ongoing shift towards POCUS integration in clinical practice.
\end{abstract}

Keywords Physical examination $\cdot$ POCUS $\cdot$ Ultrasonography $\cdot$ Free fluid $\cdot$ Ascites $\cdot$ Pleural effusion

\section{Introduction}

Antonio Leidi and Antoine Saudan contributed equally to the study

Olivier Grosgurin

Olivier.Grosgurin@hcuge.ch

Antonio Leidi

Antonio.Leidi@hcuge.ch

Antoine Saudan

Antoine.Saudan@hcuge.ch

Guillaume Soret

Guillaume.Soret@hcuge.ch

Frédéric Rouyer

Frederic.Rouyer@hcuge.ch

Christophe Marti

Christophe.Marti@hcuge.ch
Physical examination (PE), historically considered as an essential component of medical practice and part of the identity of physicians [1], is nowadays highly debated. Several reasons have been advanced, going from technological

Jérôme Stirnemann

Jerome.Stirnemann@hcuge.ch

Jean-Luc Reny

Jean-Luc.Reny@hcuge.ch

1 General Internal Medicine, Department of Medicine, Geneva University Hospitals, Geneva, Switzerland

2 Faculty of Medicine, Geneva University, Geneva, Switzerland

3 Emergency Medicine, Department of Acute Medicine, Geneva University Hospitals, Geneva, Switzerland 
advances in imaging to loss of physicians' skills in PE practice with succeeding generations, and difficulties of society to face incertitude $[2,3]$. If on one hand, PE is still considered crucial for doctor-patient human relationship [4], on the other, diagnostic performances are often unsatisfactory $[5,6]$. Little teaching time is dedicated to PE in faculties and an alarming lack of competence has been highlighted by studies among medical students and residents [7, 8]. The detection of abdominal and pleural free fluids is of uttermost importance for diagnostic and therapeutic purposes. Several physical signs have been described for ascites and pleural effusion; most of them lack sensitivity and/or specificity [9-12]. On the contrary, ultrasonography (US) is considered as the gold standard for ascites and pleural effusion detection; it can reveal fluid volumes of less than $100 \mathrm{ml}$ and $20 \mathrm{ml}$ in the peritoneal cavity and the pleura, respectively [12-14]. Even in unexperienced hands, US is more accurate than physical examination and chest X-ray [13]. Moreover, it can guide free fluid punctures raising the success rate [15] and reducing complications [16] when compared with the traditional landmark technique. Point-of-care ultrasonography (POCUS) is characterised by the bedside use of US by the front-line physician to answer focused clinical questions, guide procedures, and monitor therapies [17]. POCUS is integrated in the primary clinical evaluation along with history taking and PE [18]. The use and availability of this technology is in constant expansion in hospital and ambulatory medicine [19]. POCUS has been endorsed by international societies of internal and emergency medicine [17, 20, $21]$ and integrated in pre-graduate medical curricula [22, 23]. The detection of abdominal and pleural free fluid with POCUS is currently part of the Swiss medical school pregraduate learning objectives [24].

If the use and perceived usefulness of general PE was generally high in preceding surveys $[25,26]$, no study specifically targeted the question to abdominal and pleural free fluid recognition nor did it in relationship with POCUS use. The aim of the present study was to estimate the use of PE and POCUS in patients with suspected ascites or pleural effusion among general practitioners (GP), internal medicine (IM) and emergency medicine (EM) physicians, working in French-speaking part of Switzerland. In addition, selfreported confidence in PE signs was estimated.

\section{Methods}

A web-based anonymous survey was designed to answer the following four questions: (1) use of PE (any sign) in case of suspected abdominal or pleural free fluid, (2) confidence in 4 signs of ascites (flank dullness, shifting dullness, fluid wave and 'glaçon' sign) and 5 signs of pleural effusion (dullness to percussion, asymmetric chest expansion, reduced tactile vocal fremitus, diminished breath sounds, pleural friction rub), (3) use of POCUS and (4) frequency of radiologist referral for diagnosis.

Participants replied using a 5-point Likert scale if they used ( $1=$ "Strongly agree" to $3=$ "Neutral" to $5=$ "Strongly disagree") the previously reported PE signs in their common practice and how frequent $(1=$ "Never" to $3=$ "Five to ten times" to $5=$ "More than twenty times") they had been using them in last three months. They additionally reported how confident ( $1=$ "Very Confident" to $3=$ "Neutral" to $5=$ "Completely unconfident") they were in these signs. For purposes of simplicity, answers on PE use were grouped in a dichotomic way in "Use" (i.e. "Strongly agree" to "Agree") and "Don't use" (i.e. "Neutral" to "Strongly disagree"). Answer on frequency were grouped in "Often" (i.e. "Five to ten times" to "More than twenty times") and "Seldom" (i.e. "Never" or "Less than five times") and answers on confidence in "Confident" (i. e. "Very confident" and "Confident") and "Unconfident" (i.e. "Neutral" to "Completely unconfident"). To estimate the global confidence in PE, a 1 to 6 score was attributed to each PE sign as follows: "Very confident" $=1$, "Confident" $=2$, "Neutral" $=3$, "Unconfident" $=4$, "Completely unconfident" $=5$; a value of 6 was attributed if PE signs were never used. A total score ranging from 9 to 54 could be obtained when all answers were added. Nine to 18 were considered as "High confidence", 19 to 36 as "Intermediate confidence" and 37 to 54 as "Low confidence". Finally, participants informed how frequent ( $1=$ "Almost ever" to $3=$ "Occasionally" to $5=$ "Never") they were using POCUS and they were referring for radiologist ultrasonography or chest X-ray. Answers were grouped in "Often" (i.e. "Almost ever" to "Often") and "Seldom “ (i.e. "Occasionally" to "Never"). Characteristics of participants were collected and included, among others, place of practice (e.g. tertiary referral hospital), obtained or targeted speciality, years of clinical practice and previous POCUS training. The original survey is available online (in French).

The survey was hosted online by a commercial site (SurveyMonkey). A link to the survey was distributed by email to 197 GPs and to the heads of internal medicine (IM) and emergency medicine (EM) departments of hospitals in French-speaking cantons of Switzerland, who would subsequently distribute it to all doctors working in their facilities. The data were recorded anonymously; an email recall was planned, but failed to be sent because of Covid-19 pandemic and subsequent clinical priorities.

Descriptive statistics were used to present characteristics of participants and results. Proportions were compared with Pearson chi-square test. A two-sided $\mathrm{P}$ value of less than 0.05 was considered to infer statistical significance. Statistical analyses were performed using SPSS, version 26. Local ethical committee confirmed that a formal approval was unnecessary for the present study. 


\section{Results}

From November 2019 to January 2020, the survey was distributed to 197 GP and to the heads of IM and EM departments of 12 hospitals in French-speaking Switzerland, who relayed it to 667 in-hospital physicians (IHP). A total of 246 physicians answered to the survey (39 GP and 207 IHP) corresponding to a total response rate of $28.5 \%$. Most participants $(77.6 \%)$ came from the Geneva lake area, worked in hospitals (59\% in tertiary-referral centres, $25 \%$ in secondary-care centres), and obtained or targeted a specialisation in internal medicine (IM) (93.1\%). It is worth noting that in Switzerland IM title is required for GP and that emergency medicine (EM) is a complementary certificate, often obtained after an IM speciality. Characteristics of participants are presented in Table 1.

\section{Physical examination}

In case of suspected abdominal or pleural free fluid, almost all respondents declared to look for PE signs of ascites and pleural effusion (90\% and $88 \%$, respectively). In-hospital physicians reported a more frequent use of PE in the last three months than did GP (70\% vs 36\% for pleural effusion, $P=0.001 ; 35 \%$ vs $5 \%$ for ascites, $P=0.001$ ). When compared with EM doctors, IM physicians tended to report a more frequent use of PE (43.3\% vs $24.6 \%$ for ascites, $P=0.015 ; 75.8 \%$ vs $69.5 \%$ for pleural effusion, $P=0.001$ ) and a greater global confidence in PE (89.3\% of high or intermediate confidence versus $84 \%, P=0.001$, Fig. 2). Most participants reported to be relatively confident in conventional signs of pleural effusion (91\% for diminished breath sounds and $80 \%$ for dullness to percussion) and ascites (66\% for flank dullness). However, more than half declared to have no confidence in most of the remaining signs. No significant difference was observed between regions of work for frequency of use and confidence. Table 2 reports proportions of confidence in PE as evaluated in our survey, along with sensitivity, specificity, positive, and negative likelihood ratios for each of PE signs as reported in previous systematic reviews and meta-analyses $[10,11]$.

\section{Point-of-care ultrasonography}

Globally, less than two-third of respondents affirmed to frequently use POCUS in case of suspected abdominal or pleural free fluid $(57.1 \%$ for pleural effusion; $67.8 \%$ for ascites). Half of participants $(50.0 \%)$ affirmed having attended a structured POCUS course. More than three quarters $(75.9 \%)$ of participants reported to easily access to US devices at their workplace. Greater proportions of POCUS-trained physicians $(55.1 \%$ versus $23.1 \%$,
Table 1 Demographics and characteristics of study participants

\begin{tabular}{lc}
\hline Total participants, No. (\%) & $246(100)$ \\
\hline Region of work, No. (\%) & $191(77.6)$ \\
Geneva lake area & $55(22.4)$ \\
Others & \\
Place of practice, No. (\%) & $146(59)$ \\
Tertiary-referral hospital & $61(25)$ \\
Secondary-care hospital & $39(16)$ \\
Primary care & \\
Type of activity, No (\%) & $120(50)$ \\
Internal medicine & $59(24)$ \\
Emergency medicine & $39(16)$ \\
Family doctor & $24(10)$ \\
Others & \\
Obtained/Targeted speciality, No. (\%) & $215(93)$ \\
General internal medicine & $8(3.5)$ \\
Anaesthesiology & $8(3.5)$ \\
Intensive care & \\
Clinical position, No. (\%) & $103(41)$ \\
Resident & $62(25)$ \\
Chief resident & $28(11)$ \\
Attending physician & $14(6)$ \\
Chief of service & $39(16)$ \\
General practitioner & $122(50)$ \\
Years of practice, No. (\%) & \\
<5 years & $50(20.6)$ \\
5-15 years 15 years & \\
Previous structured POCUS formation, No. $(\%)$ & \\
No & \\
\hline
\end{tabular}

$P=0.001)$ and greater devices availability $(87.4 \%$ versus $15.4 \%, P=0.001)$ were reported by IHP when compared with primary-care physicians. In hospitals, a larger proportion of EM physicians declared to be POCUS-trained than did IM physicians $(77.6 \%$ versus $44.6 \%, P=0.001)$. POCUS-trained physicians reported a lower use of PE than did untrained for both ascites $(82.8 \%$ versus $93.4 \%$, $P=0.01)$ and pleural effusion $(84.3 \%$ versus $95.1 \%$, $P=0.006)$. Global confidence in PE signs was also lower for POCUS-trained doctors (23.3\% of unconfident versus $5 \%$ in untrained ones, $P=0.001)$. Moreover, POCUStrained participants mentioned a greater POCUS use in case of suspected abdominal ( $84.4 \%$ versus $50.4 \%$ of frequent users, $P<0.001)$ or pleural free fluid $(80.3 \%$ versus $33.9 \%, P<0.001)$ and lower rate of radiologist referral for diagnosis of ascites $(28.1 \%$ versus $71.3 \%, P<0.001)$ and pleural effusion $(21.3 \%$ versus $42.6 \%, P<0.001)$. The results are presented in Fig. 1, Panel AB, and Fig. 2. 
Table 2 Rate of confidence sensitivity, specificity, and likelihood ratios for physical examination signs of abdominal and pleural free fluid

\begin{tabular}{|c|c|c|c|c|c|}
\hline \multirow[t]{2}{*}{ Physical examination signs } & \multirow{2}{*}{$\begin{array}{l}\text { Fraction of } \\
\text { confident, \% }\end{array}$} & \multicolumn{4}{|c|}{ Diagnostic performances according to previous systematic reviews and meta-analyses $[10,11]$} \\
\hline & & Sensitivity $(95 \% \mathrm{CI})$ & Specificity $(95 \% \mathrm{CI})$ & Positive LR (95\% CI) & Negative LR (95\% CI) \\
\hline \multicolumn{6}{|l|}{ Abdominal free fluid } \\
\hline Flank dullness & 66 & $0.84(0.68-1.00)$ & $0.59(0.47-0.71)$ & $2.0(1.5-2.9)$ & $0.3(0.1-0.7)$ \\
\hline Fluid wave & 52.6 & & & $6.0(3.3-11.1)$ & \\
\hline Shifting dullness & 49.2 & $0.62(0.47-0.77)$ & $0.90(0.84-9.6)$ & & $0.4(0.3-0.6)$ \\
\hline ‘Glaçon’ sign & 28 & $0.77(0.60-0.88)$ & $0.72(0.63-0.81)$ & $2.7(1.9-3.9)-$ & $0.3(0.2-0.6)$ \\
\hline \multicolumn{6}{|l|}{ Pleural free fluid } \\
\hline Diminished breath sounds & 90.6 & $0.42-0.88$ & $0.83-0.90$ & $4.3-5.2 *$ & $0.2-0.6^{*}$ \\
\hline Dullness to percussion & 79.9 & $0.73(0.61-0.82)$ & $0.91(0.88-0.93)$ & $8.7(2.2-33)$ & $0.3(0.1-3.3)$ \\
\hline Reduced tactile vocal fremitus & 31.6 & 0.82 & 0.86 & $5.7(4.0-8.0)$ & $0.2(0.1-0.4)$ \\
\hline Asymmetric chest expansion & 25.2 & 0.74 & 0.91 & $8.1(5.2-12.7)$ & $0.3(0.2-0.5)$ \\
\hline Pleural friction rub & 35.9 & 0.05 & 0.99 & $3.9(0.8-18.7)$ & $1.0(0.9-1.0)$ \\
\hline
\end{tabular}

$C I$ confidence interval, $L R$ likelihood ratio.

*No pooled analysis because the data was per lung region or hemithorax, not per patient

\section{Work experience}

Globally, most of physicians with $>15$ years of experience were confident in PE $(94.0 \%$ of high or intermediate confidence), whereas less than half affirmed to use POCUS to confirm presence of ascites $(49.0 \%)$ or pleural effusion (42.0\%). Proportion of confident in PE was significantly lower (83.6. $\%, P=0.001)$ and POCUS use greater $(73.0 \%$ and $62.0 \%$ respectively, $P=0.001$ ) in less experienced doctors. As a result, senior doctors declared referring more frequently to radiologist for diagnosis (77.0\% versus $44.0 \%$ for ascites, $46.0 \%$ versus $28.0 \%$ for pleural effusion, $P=0.012$ ). The results are presented in Fig. 1, Panel CD, and Fig. 2.

\section{Discussion}

We observed that PE is frequently performed for diagnosis of ascites and pleural effusion by both ambulatory and in-hospital physicians. If most of them reported to be confident in component of conventional PE (abdominal flank dullness, diminished breath sounds, and dullness to thorax percussion), rates of confidence were significantly lower for the other clinical signs. Interestingly, there was no apparent relationship between reported confidence and diagnostic performances, with lower confidence given to signs with better likelihood ratios (e.g., reduced tactile vocal fremitus and asymmetric chest expansion, see Table 2). Only $62.0 \%$ of participants declared a regular use of POCUS, despite growing evidence of superiority over $\mathrm{PE}$ regarding the detection of free fluids [27]. POCUS use tends to be greater in workplaces with higher US devices availability, in younger and in POCUS-trained physicians. In contrast, senior clinicians tend to be more confident in $\mathrm{PE}$, to have a minor employ of POCUS and refer more to radiologists for diagnosis. In a previous study, 2864 physicians were surveyed on the value of PE with questions on the usefulness and frequency of use of $58 \mathrm{PE}$ signs for a large variety of diagnoses [25]. For ascites and pleural effusion, participants were surveyed on two PE signs. Abdominal percussion for ascites and chest percussion for abnormal dullness were deemed useful by $90 \%$ and $91 \%$ of respondents, respectively, while their reported frequency of use was lower, around $70 \%$. In the present study, we surveyed physicians on their perceived confidence in nine PE signs; thus, focusing the investigation on the clinical approach to patients with suspected ascites or pleural effusion. Although not directly comparable with the usefulness and frequency of use, our results on the perceived confidence in the above mentioned two main PE signs are similar to those of this previous survey. Importantly, our survey extends these findings by providing insight into various interactions between the perceived confidence in PE signs 
Fig. 1 Physical examination and POCUS use according to previous POCUS training (Panel AB) and years of clinical experience (Panel CD)
A

Pleural effusion

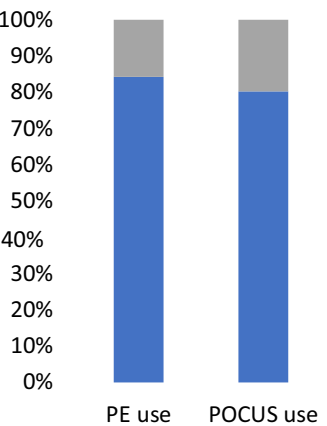

With POCUS training

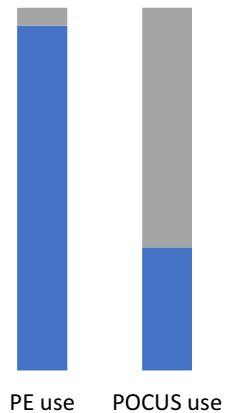

Without POCUS training
B

Ascites
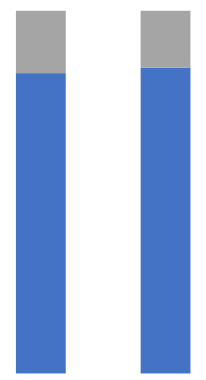

PE use

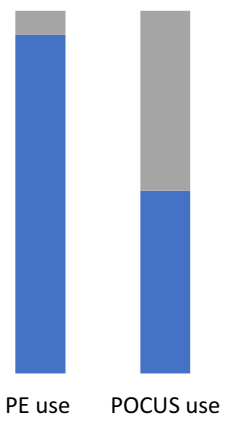

With POCUS training Without POCUS training - Use/Often Don't use/Seldom

\section{C}

$100 \%$
$90 \%$
$80 \%$
$70 \%$
$60 \%$
$50 \%$
$40 \%$
$30 \%$
$20 \%$
$10 \%$
$0 \%$

Pleural effusion

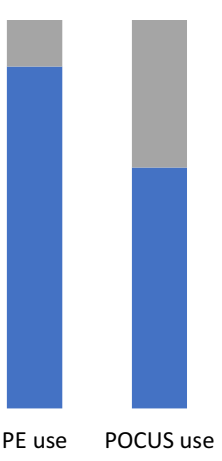

Less than 15 years

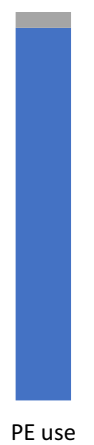

D

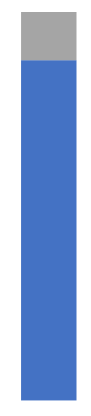

PE use
Ascites
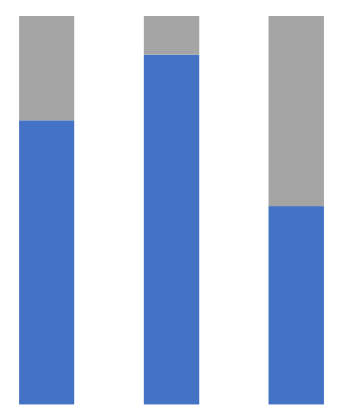

PE use POCUS use

More than 15 years

More than 15 years

Less than 15 years

More than 15 years

Fig. 2 Global confidence in physical examination according to type of activity, previous POCUS training, and years of clinical experience

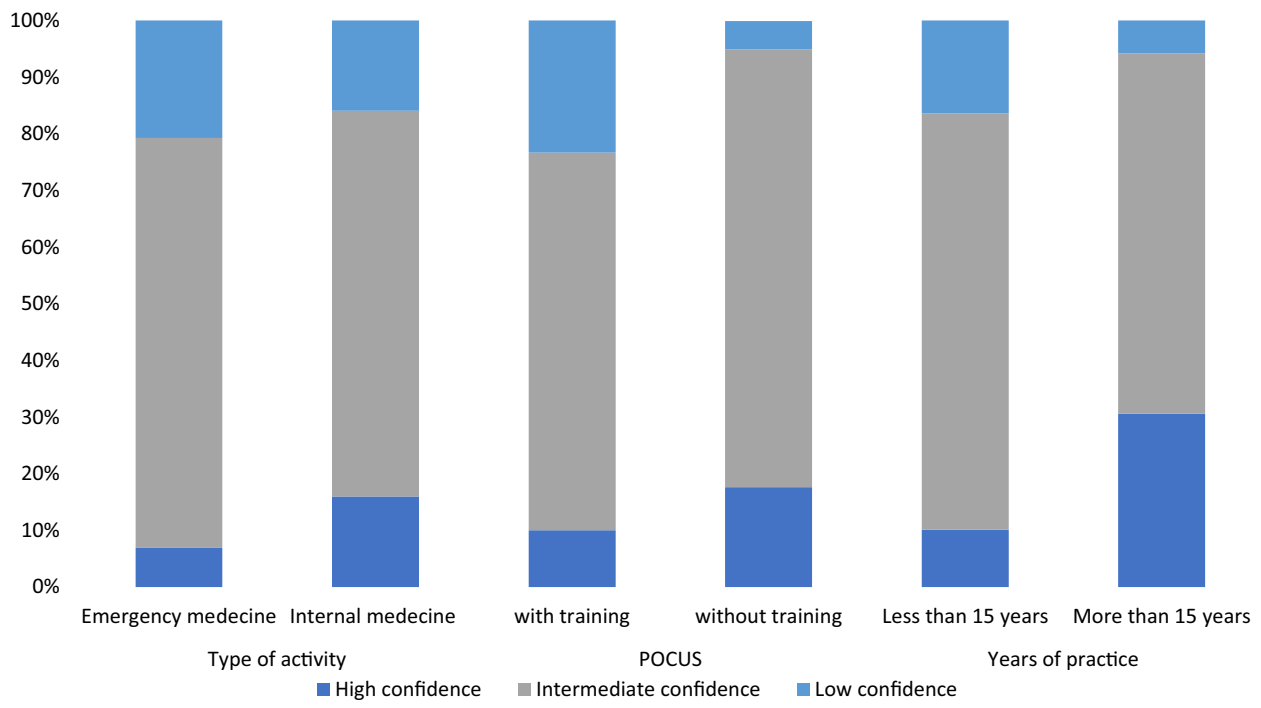


and practice of POCUS, clinical experience, and clinical setting.

Almost 30 years after the advent of POCUS [28], this valuable tool is yet incompletely integrated in clinical practice. Resistance within the medical community in adoption of innovations is a well-known phenomenon [29] particularly affecting senior physicians. Other barriers to POCUS implementation have been previously identified and include insufficient training time, unavailability of trainers, absence of structured curricula, material and financial support, as well as lack of consideration by US specialist [6, 30-32]. In Switzerland, particularly in the French-speaking part, these barriers have been predominant in the early 2000s and are now slowly overcame due to the implication of a growing population of POCUS leaders.

POCUS was initially developed in intensive care and EM; it is much more integrated in clinical practice in these specialities when compared with IM, being on the contrary a late POCUS-adopter discipline [18]. Furthermore, mastering of extended focused assessment with sonography for trauma (eFAST) is required for the complementary certification in EM, whereas no specific POCUS competence is yet necessary for obtaining IM title in Switzerland. For these reasons, we observed a greater proportion of EM physicians having attended a structured course and using POCUS compared with IM IHP or GP. Interestingly, in our survey lower use and confidence in PE was reported by participants affirming a greater POCUS use. This may be due to POCUS better diagnostic accuracy or may be related to the higher trust given by new generations of physicians to technologies or to their ability in integrating innovations. Globally, these results suggest that a shift of practice toward integration of POCUS has started and may become evident in next decades.
The present study has several limitations. First, less than one third of contacted physicians answered to the survey. Although low, this is usual in such professional surveys [33] and slightly greater than the answer rate obtained in the previously reported international survey (24\%) [25]. Second, the use of PE for ascites and pleural effusion was asked with two general questions, preventing us to conclude about the frequency of use of each previously described PE signs. Indeed, regarding these specific signs, only their attributed confidence was reported. Some of these signs being detected by routine $\mathrm{PE}$ (e.g. bilateral lung auscultation and abdominal percussion), frequency of use of PE in last 3 months could be overestimated in IHP, due to the custom of performing a baseline complete PE in all hospitalized patients. Finally, the survey was limited to the French-speaking cantons of Switzerland and conclusion may not be generalizable to other regions or countries. In fact, POCUS is much more integrated in German-speaking part of Switzerland, as suggested by a recent cross-sectional survey among GP, reporting a frequent POCUS use for half of participants [34], as compared to only $15.4 \%$ of GP included in our survey. This is unlikely to lessen the differences observed in the present survey, but should rather strengthen them.

In conclusion, PE still occupies a central place in detection of free fluids. The established POCUS superiority over PE signs for fluid detection, however, has introduced a progressive change of practice that may become evident in the following generations of physicians. As it happened with the revolutionary advent of stethoscope 200 years ago, POCUS should be progressively integrated and enhance physical examination, instead of replacing it. For this reason, teaching efforts should be placed in valuable components of PE and in developing structured POCUS training. 


\section{Appendix 1}

Study questionary (French).

\section{Annexe 1}

Q1 : Canton :

Genève

Vaud

Neuchâtel

Fribourg

Valais

Jura

Berne

Q2 : Type d'établissement :

Cabinet isolé

Groupe de cabinet

Clinique privée

Hôpital de petite taille

Hôpital de grande taille

Q3 : Titre FMH principal (visé/obtenu) :

Q4 : Années de pratique post-graduée :

Q5 : Pour les médecins hospitaliers, fonction

dans l'institution :

Médecin interne

Chef de clinique

Médecin adjoint

Chef de Service

Q6 : Avez-vous déjà suivi une formation structurée en échographie :

Oui

Non

Q7 : Avez-vous à disposition facilement un échographe que vous pouvez utiliser vousmême?

Oui

Non

Q8 : Avez-vous à disposition facilement un appareil de radiographie standard ?

Oui

Non

Q9 : Lors d'une suspicion anamnestique d'ascite recherchez-vous des signes cliniques ?

Tout à fait d'accord

D'accord

$\mathrm{Ni}$ en désaccord ni d'accord

Pas d'accord

Pas du tout d'accord

Si vous en recherchez, pouvez-vous préciser pour chacun d'entre eux (voir ci-dessous) la confiance diagnostique que vous portez à ces signes (Pas du tout d'accord = pas recherchél pas d'accord = pas important/ Ni en désaccord ni d'accord=peu important/ D'accord = assez importante, Tout à fait d'accord=très importante)

Q10 : Matité latérale avec tympanisme périombilical à la percussion en décubitus dorsal :

Tout à fait d'accord

D'accord

Ni en désaccord ni d'accord

Pas d'accord

Pas du tout d'accord

Q11 : Matité du flanc inférieur à la percussion en décubitus latéral :

Tout à fait d'accord

D'accord

Ni en désaccord ni d'accord

Pas d'accord

Pas du tout d'accord

Q12 : Signe du flot :

Tout à fait d'accord

D'accord

Ni en désaccord ni d'accord

Pas d'accord

Pas du tout d'accord

Q13 : Signe du glaçon :

Tout à fait d'accord

D'accord

Ni en désaccord ni d'accord

Pas d'accord

Pas du tout d'accord

Q14 : Ces 3 derniers mois, combien de fois avez-vous recherché au moins un de ces signes pour la recherche d'ascite?

Jamais

Moins de 5 fois

5 à 10 fois

10 à 20 fois

Plus de 20 fois

Q15 : Face à une suspicion d'ascite, dans quelle proportion des cas effectuez-vous vous-même une échographie abdominale pour rechercher de l'ascite?

Presque toujours

Souvent

Rarement

Presque jamais

Jamais 
Q16 : Face à une suspicion d'ascite, dans quelle proportion des cas faîtes-vous appele à un radiologue (ou un collègue compétent pour recherche du liquide libre avec un échographe)

Presque Toujours

Souvent

Rarement

Presque jamais

Jamais

Q17 : Lors d'une suspicion d'un épanchement pleural, recherchez-vous des signes cliniques?

Presque toujours

Souvent

Rarement

Presque jamais

Jamais

Si vous en recherchez, pouvez-vous préciser la confiance diagnostique que vous portez à ces signes (Pas du tout d'accord = pas recherchél pas d'accord = pas important/ Ni en désaccord ni d'accord=peu important/ D'accord = assez importante, Tout à fait d'accord=très importante)

Q18: Percussion à la recherche d'une matité :

Tout à fait d'accord

D'accord

Ni en désaccord ni d'accord

Pas d'accord

Pas du tout d'accord

Q19 : Expansion d'un hémithorax diminué :

Tout à fait d'accord

D'accord

$\mathrm{Ni}$ en désaccord ni d'accord

Pas d'accord

Pas du tout d'accord

Q20 : Fremitus tactile diminué :

Tout à fait d'accord

D'accord

Ni en désaccord ni d'accord

Pas d'accord

Pas du tout d'accord

Q21 Murmure vésiculaire aboli :

Tout à fait d'accord

D'accord

$\mathrm{Ni}$ en désaccord ni d'accord

Pas d'accord
Pas du tout d'accord

Q22 : Frottement pleural :

Tout à fait d'accord

D'accord

Ni en désaccord ni d'accord

Pas d'accord

Pas du tout d'accord

Q23 : Ces 3 derniers mois, combien de fois avez-vous recherché- au moins un de ces signes pour la recherche d'épanchement pleural ?

Jamais

Moins de 5 fois

5 à 10 fois

10 à 20 fois

Plus de 20 fois

Q24 : Face à une suspicion d'épanchement pleural, dans quelle proportion des cas effectuez-vous vous-même une échographie pleurale pour rechercher de l'ascite?

Presque toujours

Souvent

Rarement

Presque jamais

Jamais

Q25 : Face à une suspicion d'épanchement pleural, dans quelle proportion des cas faîtes-vous appel à un radiologue (ou un collègue compétent pour recherche du liquide libre avec un échographe)

Presque toujours

Souvent

Rarement

Presque jamais

Jamais

Q26 : Face à une suspicion d'épanchement pleural, dans quelle proportion des cas effectuez-vous une radiographie du thorax ? Presque toujours

Souvent

Rarement

Presque jamais

Jamais 
Acknowledgements The authors are grateful to Prof Reny, Prof Sarasin, Prof Guessous and Dr Zekry (Geneva University Hospitals, HUG, Geneva), to Prof Kherad and Dr Dussoix (Hospital of La Tour, Geneva), Prof Vollenweider and Prof Carron (Lausanne University Hospital, CHUV, Lausanne), Prof Fumeaux and Dr Bieler (Hospital of Nyon, GHOL, Nyon), Prof Cometta (Hospital of Yverdon-les-Bains, Yverdon-les-Bains), Prof Garin and Dr Pfeil (Hospital of Rennaz, HRC, Rennaz), Prof Petignat and Dr Frochaux (Hospital of Sion, HVS, Sion), Prof Zender and Prof Donze (Hospital of Neuchâtel, RHNe, Neuchâtel), Prof Hayoz and Prof Ribory (Hospital of Fribourg, HFR, Fribourg) and Dr Duplain (Hospital of Jura, H-Ju, Delémont) for distributing the survey to the physicians working in their hospitals and to all participants who answered to our questions.

Author contributions The idea for this article originally came from OG. AS and OG designed and conducted the survey, had full secured access to data and preformed the statistical analyses. AL, AS, and OG carried out the literature search, conceptualized and wrote the first draft of the manuscript. All authors have read, critically revised, and approved the final version of this manuscript.

Funding Open Access funding provided by Université de Genève. No other funding sources.

Availability of data and materials Our data are accessible to researchers upon reasonable request for data sharing to the corresponding author.

\section{Declarations}

Conflict of interests The authors declare that they have no conflict of interest.

Open Access This article is licensed under a Creative Commons Attribution 4.0 International License, which permits use, sharing, adaptation, distribution and reproduction in any medium or format, as long as you give appropriate credit to the original author(s) and the source, provide a link to the Creative Commons licence, and indicate if changes were made. The images or other third party material in this article are included in the article's Creative Commons licence, unless indicated otherwise in a credit line to the material. If material is not included in the article's Creative Commons licence and your intended use is not permitted by statutory regulation or exceeds the permitted use, you will need to obtain permission directly from the copyright holder. To view a copy of this licence, visit http://creativecommons.org/licenses/by/4.0/.

\section{References}

1. Kelly MA, Freeman LK, Dornan T (2019) Family physicians' experiences of physical examination. Ann Fam Med 17(4):304-310

2. Feddock CA (2007) The lost art of clinical skills. Am J Med 120(4):374-378

3. Jauhar S (2006) The demise of the physical exam. N Engl J Med 354(6):548-551

4. Asif T, Mohiuddin A, Hasan B, Pauly RR (2017) Importance Of Thorough Physical Examination: A Lost Art. Cureus 9(5):e1212

5. Simel DL, Rennie D, Keitz SA. The rational clinical examination: evidence-based clinical diagnosis: McGraw-Hill Medical New York, NY; 2009.

6. Narula J, Chandrashekhar Y, Braunwald E (2018) Time to add a fifth pillar to bedside physical examination: inspection, palpation, percussion, auscultation, and insonation. JAMA Cardiol 3(4):346-350

7. Haring CM, Cools BM, van der Meer JW, Postma CT (2014) Student performance of the general physical examination in internal medicine: an observational study. BMC Med Educ 14:73

8. Sharma S (2011) A single-blinded, direct observational study of PGY-1 interns and PGY-2 residents in evaluating their historytaking and physical-examination skills. Perm J 15(4):23-29

9. Cattau EL Jr, Benjamin SB, Knuff TE, Castell DO (1982) The accuracy of the physical examination in the diagnosis of suspected ascites. JAMA 247(8):1164-1166

10. Williams JW Jr, Simel DL (1992) The rational clinical examination. Does this patient have ascites? How to divine fluid in the abdomen. JAMA 267(19):2645-2648

11. Wong CL, Holroyd-Leduc J, Straus SE (2009) Does this patient have a pleural effusion? JAMA 301(3):309-317

12. Kalantri S, Joshi R, Lokhande T, Singh A, Morgan M, Colford JM Jr et al (2007) Accuracy and reliability of physical signs in the diagnosis of pleural effusion. Respir Med 101(3):431-438

13. Liu RB, Donroe JH, McNamara RL, Forman HP, Moore CL (2017) The practice and implications of finding fluid during point-of-care ultrasonography: A review. JAMA Intern Med 177(12):1818-1825

14. Lobo V, Weingrow D, Perera P, Williams SR, Gharahbaghian L (2014) Thoracic ultrasonography. Crit Care Clin 30(1):93-117v-vi

15. Nazeer SR, Dewbre H, Miller AH (2005) Ultrasound-assisted paracentesis performed by emergency physicians vs the traditional technique: a prospective, randomized study. Am J Emerg Med 23(3):363-367

16. Mercaldi CJ, Lanes SF (2013) Ultrasound guidance decreases complications and improves the cost of care among patients undergoing thoracentesis and paracentesis. Chest 143(2):532-538

17. Guidelines U (2017) Emergency, point-of-care and clinical ultrasound guidelines in medicine. Ann Emerg Med 69(5):e27-e54

18. Leidi A, Rouyer F, Marti C, Reny JL, Grosgurin O (2020) Point of care ultrasonography from the emergency department to the internal medicine ward: current trends and perspectives. Intern Emerg Med. https://doi.org/10.1007/s11739-020-02284-5

19. Bobbia X, Abou-Badra M, Hansel N, Pes P, Petrovic T, Claret PG et al (2018) Changes in the availability of bedside ultrasound practice in emergency rooms and prehospital settings in France. Anaesth Crit Care Pain Med 37(3):201-205

20. Ma IWY, Arishenkoff S, Wiseman J, Desy J, Ailon J, Martin $\mathrm{L}$ et al (2017) Internal medicine point-of-care ultrasound curriculum: consensus recommendations from the canadian internal medicine ultrasound (CIMUS) Group. J Gen Intern Med 32(9):1052-1057

21. Torres-Macho J, Aro T, Bruckner I, Cogliati C, Gilja OH, Gurghean A et al (2020) Point-of-care ultrasound in internal medicine: A position paper by the ultrasound working group of the European federation of internal medicine. Eur J Intern Med 73:67-71

22. Hoppmann RA, Rao VV, Bell F, Poston MB, Howe DB, Riffle S et al (2015) The evolution of an integrated ultrasound curriculum (iUSC) for medical students: 9-year experience. Crit Ultrasound J 7(1): 18

23. Heinzow HS, Friederichs H, Lenz P, Schmedt A, Becker JC, Hengst $\mathrm{K}$ et al (2013) Teaching ultrasound in a curricular course according to certified EFSUMB standards during undergraduate medical education: a prospective study. BMC Med Educ 13:84

24. Sohrmann M, Berendonk C, Nendaz M, Bonvin R (2020) Swiss Working Group For Profiles I. Nationwide introduction of a new competency framework for undergraduate medical curricula: a collaborative approach. Swiss Med Wkly 150:w20201 
25. Elder AT, McManus IC, Patrick A, Nair K, Vaughan L, Dacre J (2017) The value of the physical examination in clinical practice: an international survey. Clin Med (Lond) 17(6):490-498

26. Wu EH, Fagan MJ, Reinert SE, Diaz JA (2007) Self-confidence in and perceived utility of the physical examination: a comparison of medical students, residents, and faculty internists. J Gen Intern Med 22(12):1725-1730

27. Soni NJ, Franco R, Velez MI, Schnobrich D, Dancel R, Restrepo MI et al (2015) Ultrasound in the diagnosis and management of pleural effusions. J Hosp Med 10(12):811-816

28. Moore CL, Copel JA (2011) Current concepts point-of-care ultrasonography. New Engl J Med 364(8):749-757

29. Barrett PM, Topol EJ (2016) To truly look inside. Lancet 387(10025):1268-1269

30. Rajamani A, Miu M, Huang S, Elbourne-Binns H, Pracher F, Gunawan S et al (2019) Impact of critical care point-of-care ultrasound short-courses on trainee competence. Crit Care Med 47(9):e782-e784
31. Gold DL, Marin JR, Haritos D, Melissa Skaugset L, Kline JM, Stanley RM et al (2017) Pediatric emergency medicine physicians' use of point-of-care ultrasound and barriers to implementation: A Regional Pilot Study. AEM Educ Train 1(4):325-333

32. Mengel-Jørgensen T, Jensen MB (2016) Variation in the use of point-of-care ultrasound in general practice in various European countries. Results of a survey among experts. Eur J Gen Pract 22(4):274-277

33. Weaver L, Beebe TJ, Rockwood T (2019) The impact of survey mode on the response rate in a survey of the factors that influence Minnesota physicians' disclosure practices. BMC Med Res Methodol 19:73

34. Touhami D, Merlo C, Hohmann J, Essig S (2020) The use of ultrasound in primary care: longitudinal billing and cross-sectional survey study in Switzerland. BMC Fam Pract 21(1):127

Publisher's Note Springer Nature remains neutral with regard to jurisdictional claims in published maps and institutional affiliations. 